\title{
Sensitivity of vegetation indices in relation to parameters of Norway spruce stands
}

\author{
Aneta Modzelewska ${ }^{1} \bowtie$, Krzysztof Stereńczak ${ }^{1}$, Monika Mierczyk ${ }^{1}$, Sylwia Maciuk ${ }^{1}$, \\ Radomir Bałazy ${ }^{1}$, Tomasz Zawiła-Niedźwiecki ${ }^{2}$ \\ ${ }^{1}$ Forest Research Institute, Department of Forest Resources Management, Braci Leśnej 3, 05-090 Raszyn, Poland, \\ phone: +48 22 7150327, e-mail: a.modzelewska@ibles.waw.pl \\ ${ }^{2}$ Directorate General of the State Forests, Grójecka 127, 02-124 Warszawa, Poland
}

\section{Abstract}

The main goal of this research is to shed further light on the sensitivity of the vegetation indices to spatial changes of stand parameters. The analysis was done within mountain forests in the Sudetes and the Beskids in southern Poland. Some 1327 stands were analysed with more than 70 percent of spruce contribution in the species composition. The response of selected vegetation indices was verified in relation to the alterations of spruce participation, stand height, volume, stand density and diameter. The following indices were analysed: Normalized Difference Vegetation Index, Normalized Difference Red Edge Index, Green Normalized Difference Vegetation Index and Wide Dynamic Range Vegetation Index. Indices were calculated based on the Rapid Eye (Black Bridge) images. All the analysed stand characteristics influence the values of vegetation indices. In general: mean height, diameter at breast height, volume and spruce participation are the most negatively correlated with the indices. Density is a variable that, in general, cannot directly be used for indices correction, because it is hard to find any stable trend. NDRE is the most stable index for the analysis of stand characteristics.

\section{KeY WORDS}

vegetation indices, stand characteristics, mountain forest, Rapid Eye, Red Edge, Norway spruce

\section{INTRODUCTION}

The decreasing amount of forest-covered area may have a negative influence on the whole Earth's environment. Despite efforts to protect forests and the continuous increase of forest areas in Europe and China, their global acreage is still reducing (FAO 2016). Forests, especially in the mountains, are exposed to permanent stress related to severe climate conditions, water availability, fungi and insects. One of the main problems in spruce dominated forests are bark beetle infestations. The insect usually attacks areas with poorer health status (Jenkins et al. 2008). Older trees with less vitality or large diameters are especially endangered (Covington et al. 1997). There might be some association between bark beetle attacks and fire hazard (Hicke et al. 2012). Previous studies demonstrated that Burn Ratio Index can be used to detect bark beetle attacks (Meigs et al. 2011). As there is a correlation be- 
tween fire risk and vegetation condition (Woźniak 2011), and between vegetation health and insect attack, indices can be used to detect points of insect gradation.

Remote sensing data can be successfully used in the monitoring of forest health, especially in large areas, where local field measurements are not sufficient. The use of spectral vegetation indices is common, usually involving broadband indices concerning differences between near infrared and other bands. As far as indices are used to measure whether the vegetation is in good condition or not, their sensitivity to spatial changes of the environmental and forest variables is not fully understood (Jackson and Heute 1991; Houghton et al. 2001; Lu et al. 2004). There are differences in the indices connected with the changes in temporal, spatial and biophysical variables, such as the variations of LAI, chlorophyll content, trees volume, biomass and diameter (Foody et al. 2001; Xiao et al. 2014; Gitelson 2004; Lu et al 2004). Forest structure and species composition affect the values of vegetation indices as well. When analysing the Rapid Eye images with $5 \mathrm{~m}$ spatial resolution, it should be considered that inside a pixel, there can be a crown or mixture of crowns and background or background only when a whole pixel is inside a gap. It means that the variation in the indices can be very high, especially when the analysed area is covered with various kinds of trees, where the tree crowns may have different sizes. To eliminate such a problem, in this study, we focused on the stands with Norway Spruce as a dominant species composition.

For determining and isolating the indices heavily influenced by stand characteristics, health monitoring results can be of help when the process is restricted to the forest condition (Todd and Hoffer 1998; Freitas et al. 2005).

The most common and broadly used analysis is the Normalized Difference Vegetation Index - NDVI (Rouse et al. 1973). It is devised as a normalized modification of Simple Ratio (Jordan 1969), the first index based on the differences between infrared and red bands. Although NDVI is sensitive to plant vitality, there are some disadvantages as well (Henerby et al. 2004), which have prompted the development of modifications to improve the NDVI results for some specific applications. The sensitivity to background reflectance is one such limitation (Heute 1998; Rocha and Shaver 2009) that led to the NDVI-modification. NDVI is also not sensitive to variations of LAI, when the LAI value is higher than 2 (Henerby et al. 2004). For this reason, Wide Dynamic Range Vegetation Index - WDRVI, was developed (Gitelson 2004). Another modification is Green Normalized Difference Vegetation Index, which uses green band (instead of red), as it is more sensitive to biophysical changes in plants (Gitelson et al. 1996).

On the other hand, the red-edge spectrum is sensitive to plant condition changes, so it can be useful to detect woodland stress. Usually, it is available only in hyperspectral data, but there are some sensors with red-edge band, such as Rapid Eye or SumbandilaSat. The comparison of imagery proved that the red-edge band improves detecting changes in vegetation condition (Cho et al. 2012). Decreasing the reflectance in that band is usually related to lower vitality of trees. Indices using red-edge, for example, the Normalized Difference Red Edge Index - NDRE (Barnes et al. 2000), are known to detect stress or any forest health decrease better than NDVI (Eitel et al. 2011).

Previous research applied time series to estimate the temporal changes, for example, the use of the Landsat TM data in the conifer forests attacked by the bark beetle (Meigs et al. 2011). Spectral trajectories were acquired and analysed to detect these changes in woodlands. Studies showed that there are connections between spectral trajectory changes and insect attacks, but temporal changes are difficult to capture in heterogeneous woodland. Vegetation indices were also compared with the forest stand parameters. As the traditional spectral indices tend to depend a lot on parameters of stands, which means that higher values may be rather related to stand density or volume than to forest health. For proper examination of the health state, indices should rather be independent of the forest stand parameters (Lu et al. 2004).

This research focuses on Norway spruce (Picea abies), which is now, because of climate changes, one of the high-risk species in Poland (Rykowski 2008). With the use of Rapid Eye imagery featuring red-edge band, the objective of this research was to study the sensitivity of selected vegetation indices to spatial changes of biophysical stands parameters, in order to define the amount of variation in vegetation indices values caused specifically by the stands, and not by their vigour or health condition. The analysed parameters are spruce participation, height, volume, stand density and diameter. 


\section{Material And Methods}

\section{Research area}

The research was performed in three different areas of mountain forests located in southern Poland (Fig. 1).

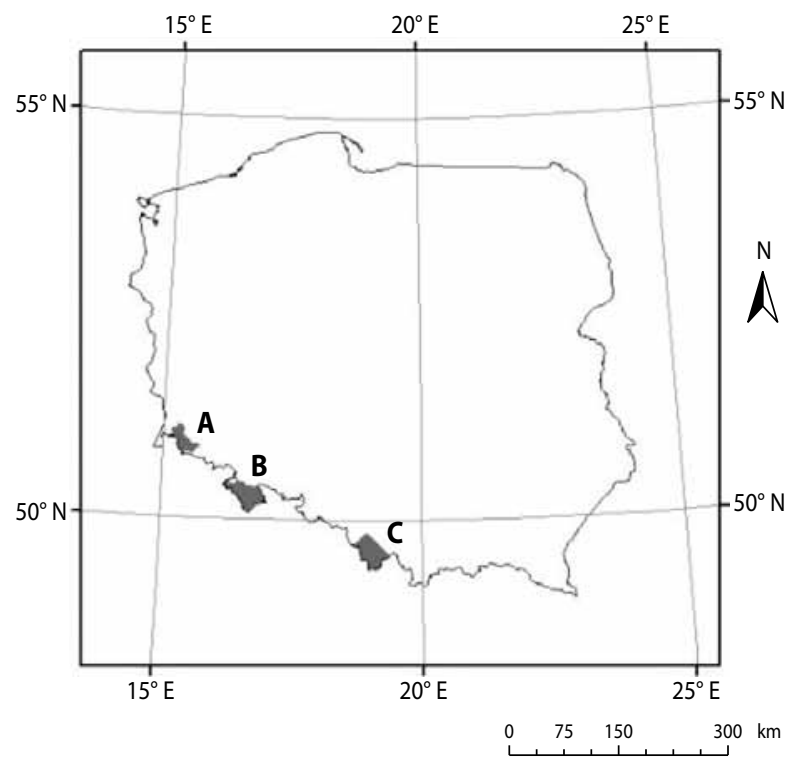

Figure 1. Location of the research objects (map elaborated by $\mathrm{T}$. Hycza)

The research object A ('A-area') is located in southwest Poland and covers $292.4 \mathrm{~km}^{2}$. The main species are: spruce $(72 \%)$, pine $(10 \%)$, birch $(9 \%)$, oak $(5 \%)$ and beech (3\%). Almost half of the stands of this object are between 20-60 years old. Only $1 \%$ of the area is covered by non-forested land and about $13 \%$ is in the regeneration phase (Forest Data Bank 2014). The 'B-area' is located in the southern part of the Lower Silesian Voivodeship and covers $495.5 \mathrm{~km}^{2}$. The main forest species are: spruce $(83 \%)$, beech $(8 \%)$, pine $(4 \%)$, oak $(2 \%)$ and birch (1\%). The age structure is more even with average share of $13 \%$ for each of the age classes. $23 \%$ of the B-area is covered by terrain in the regeneration phase (Forest Data Bank 2014). The last research object ('C-area') is located in the Beskid Ślaski and Beskid Żywiecki Mountains in the southern part of the Silesian Voivodeship and covers $489.5 \mathrm{~km}^{2}$. The main forest species are: spruce (61\%), beech (23\%), pine (5\%), fir $(4 \%)$, oak (3\%), birch (2\%) and alder (1\%). About $14 \%$ of the forested area is covered by trees in the 1st age class, $16 \%$ in the 2 nd age class, $12 \%$ in the 3 rd age class,
$13 \%$ in the 4 th age class, $9 \%$ in the 5 th age class, $5 \%$ in the 6 th age class and 3\% in the 7 th age class. $26 \%$ of the $\mathrm{C}$-area is in the regeneration phase (Forest Data Bank 2014).

\section{Data}

The Rapid Eye (present name is Black Bridge) images were used, which were acquired on 16th June 2012 (B-area), 8th July 2012 (A-area) and 24th July 2012 (C-area), in the part of vegetation season, which makes them comparable. All the pre-processing of Rapid Eye images was executed by the company providing the data. That included: orthorectification, geometric and atmospheric corrections. The imagery was acquired in five spectral bands with spatial resolution of $6.5 \mathrm{~m}$, but the final product provided by company is resampled to $5 \mathrm{~m}$. There are five Rapid Eye spectral bands (Fig. 2): blue (B) - 440-510 nm, green (G) - 520-590 nm, red (R) - 630-685 nm, red edge (RE) - 690-730 nm, near infrared (NIR) - 760-850 nm. Apart from the blue band, each of these bands is useful in the vegetation analysis and were used for indices calculation (Weichelt et al. 2014).

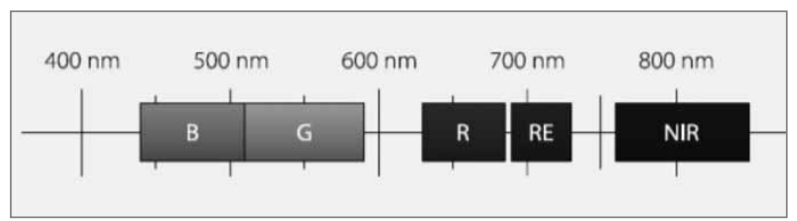

Figure 2. Rapid Eye spectral bands (Weichelt et al. 2014)

\section{Indices}

The selected indices are commonly used to detect lack of vegetation vitality or stress and are suitable for forested areas.

Normalized Difference Vegetation Index (Rouse et al. 1973) is sensitive to plant condition and uses red and near infrared bands. The index values can range from -1 to 1 . Areas without vegetation receive values below 0.2 and those with good vegetation vitality range between 0.6 and 1 (Weier and Herring 2000).

$$
\mathrm{NDVI}=(\mathrm{NIR}-\mathrm{RED}) /(\mathrm{NIR}+\mathrm{RED})
$$

Normalized Difference Red Edge Index (Barnes et al. 2000) is a modification of NDVI, which uses red edge band instead of red band. According to the previ- 
ous studies, NDRE can detect stress in woodlands earlier (Eitel et al. 2011) and is more sensitive to changes in chlorophyll content (Barnes et al. 2000).

$$
\mathrm{NDRE}=(\mathrm{NIR}-\mathrm{RE}) /(\mathrm{NIR}+\mathrm{RE})
$$

Green Normalized Vegetation Index (Gitelson et al. 1996) is also a modification of NDVI that in turn uses the green band instead of the red one. The response in green reflectance is associated more to the biophysical variables of vegetation and chlorophyll content (Buschmann and Nagel 1993).

$$
\text { GNDVI }=(\text { NIR }- \text { GREEN }) /(\text { NIR }+ \text { GREEN })
$$

Wide Dynamic Range Vegetation Index (Gitelson 2004) was invented to achieve better correlation with Leaf Area Index, especially in its high values, where NDVI is not sensitive to LAI changes (Gitelson 2004).

$$
\text { WDRVI }=(0.1 \times \mathrm{NIR}-\mathrm{RED}) /(0.1 \times \mathrm{NIR}+\mathrm{RED})
$$

\section{Stand variables}

Vegetation indices were compared to the stand parameters. Such analysis was based on the digital forest stand maps in a vector format (shapefile). Each stand (management unit) had a large number of characteristics acquired during forest inventory. Each parameter was featured during field studies. In the research, only healthy stands and with at least $70 \%$ of spruce were used. The following stand parameters were chosen: stand height, stand density, volume and diameter. Height is a parameter that corresponds with the age of the trees. A typical feature of Norway spruce is its long crown, but the length of crown always depends on the tree's height. It decides about the amount of light, which is absorbed or reflected, which means that indirectly, the length of crown influences the vegetation indices. Height and diameter are variables, which are highly related to the age of the trees. Height can be measured using the remote sensing techniques, while diameter is usually measured in the field. Volume and stand density are synthetic variables that are estimated based on many individual trees features. They play significant role in forest characterization. The parameters were chosen as they were the mostly used variables to describe stand, commonly measured and utilized in forest and environmental study. These variables were considered as the most important variables in describing the forest structure.

\section{Image analysis and statistics used}

The visual interpretation of stand parameters (density, species composition and tree cover) was the first step of analysis. For the main part of the analysis, only those stands were chosen that had Norway spruce prevailing in the species structure and were without any dead trees. Finally, a total of 1327 stands were selected (469 in A-area, 275 in B-area and 583 in C-area). To avoid any spectral influence of non-forest classes (clear cuts, roads, etc.), all these elements were cut off with a buffer of $2.5 \mathrm{~m}$. In the end, the final first sample for the analysis included only forest stands. Nevertheless, it is obvious that a forest stand is not a fully homogeneous unit. Considering that, during the analysis, it was decided to compare different sample plot sizes in order to check how this variable may influence the amount of information about the forest condition and vegetation indices variability. Apart from the whole stands described above, three other options (fishnet meshes within stand, reduced surface, selected meshes) were selected in order to find some automatic and non-automatic methods of sampling (Fig. 3).

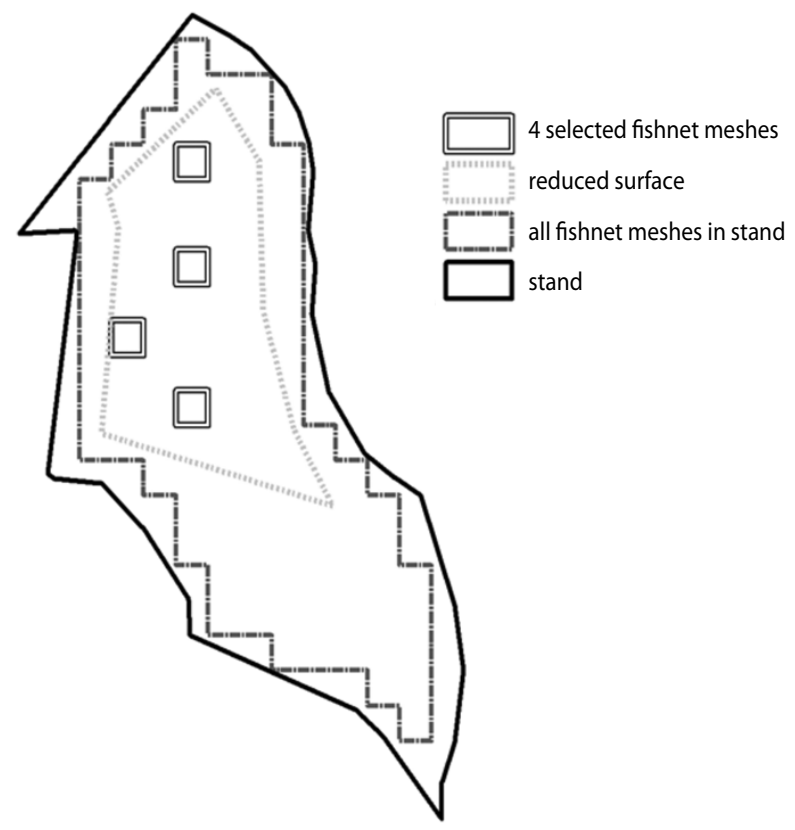

Figure 3. Samples used in analysis

In the final analysis, the following samples were used: 
1. Whole stand - the biggest, basic surface was the whole stand derived from the digital forest map.

2. Fishnet meshes in the whole stand - fishnet with $20 \mathrm{~m} \times 20 \mathrm{~m}(4 \times 4$ pixels $)$ meshes were generated. The kernel of $4 \times 4$ spectrally uniform pixels was basis for further statistical analysis. For the whole stand analysis, only fishnets completely enclosed in the stand were used. The cells located on the stand borders were eliminated to avoid the influence of mixels (spectrally mixed pixels) on spectral properties of created objects. All cells falling inside the stand borders were selected and merged together to become one object.

3. Reduced surface - areas (spectrally uniform, selected by visual interpretation), which are mostly compatible with stand characteristics. Inside each of the 1327 stands, the observer checked descriptions, corrected borders and created sub-areas where needed, which was found to be exactly concordant with inventory description.

4. Four fishnet meshes in the surface - four meshes selected by visual interpretation within the reduced surface. This random operation once again was to check, if this small, homogenous area gives similar information about health status to the one obtained in the whole stand approach. The aim was to check whether there is a necessity to subtract the area of analysis. These four fishnets were merged together to form one object in statistical analysis.

As the indices were calculated in ENVI software, the statistics were calculated in ArcGIS using its Spatial

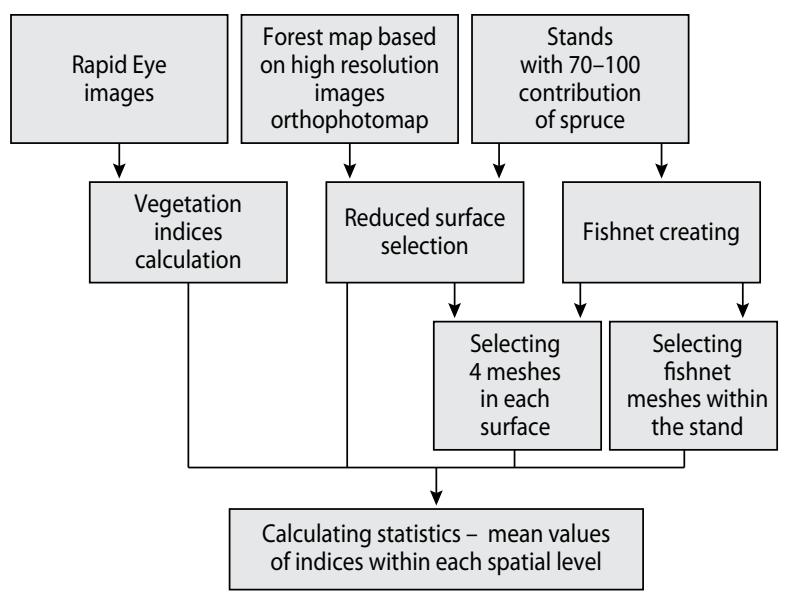

Figure 4. Scheme of the analysis
Analyst extension. The mean and standard deviation of the indices in each research area (Fig. 3) were calculated and compared. Additionally, the average coefficient of variation for each index for all sample plot standards were analysed. The full schema of analysis is presented in Figure 4.

\section{Results}

The results presented below concern the general trends in response to vegetation indices to changes in the stand variables and the individual response on each research area level.

\section{Spruce participation}

The mean value of the investigated indices always decreased with the rise of spruce participation in the species structure and was the highest for stands with more than $70 \%$ of spruce (classes 7-10). For all the indices, standard deviation was the highest when there was $80 \%$ of spruce present and then started to decrease (Fig. 5).

The mean NDVI was the lowest in reduced surface areas, while the highest values were obtained in four fishnet meshes. The curves in the graphs, which represent the whole stand and all fishnet meshes in the stand, were very similar. Standard deviation was the lowest in the smallest areas (4 fishnet meshes), and became higher with increased acreage. The curve of all fishnet meshes in stand was very close to the curve of the whole stand.

The mean NDRE also decreased with increasing spruce fraction, but the values on various surface levels are much closer to each other than in case of the NDVI values. Standard deviation on each surface level was similar to NDVI.

The GNDVI mean and standard deviation reached values similar to the previous indices. The main difference lies in the mean of the whole stand, which is much lower than the mean in the 4 meshes when the contribution of spruce is $70 \%$; but with growing spruce fraction, the mean value for the stand increases, while the mean in the 4 fishnet parts decreases.

The mean and standard deviation values for WDRVI were similar to NDVI and NDRE. Mean values of indices on different surface standards are equally a little lower in each class of spruce participation. 

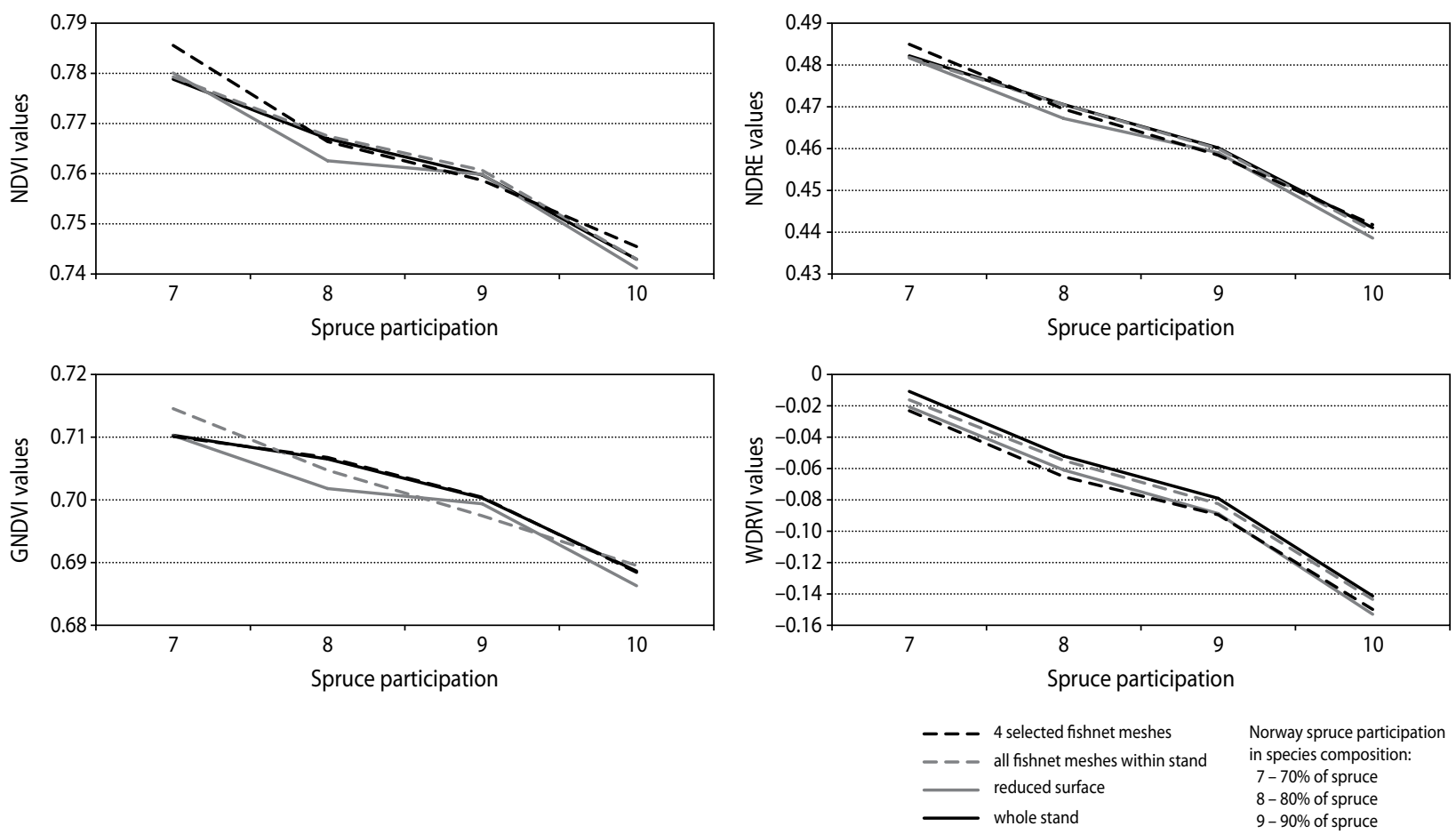

Norway spruce participation in species composition:

$7-70 \%$ of spruce $8-80 \%$ of spruce

$9-90 \%$ of spruce

$10-100 \%$ of spruce

Figure 5. Indices values compared with spruce participation classes
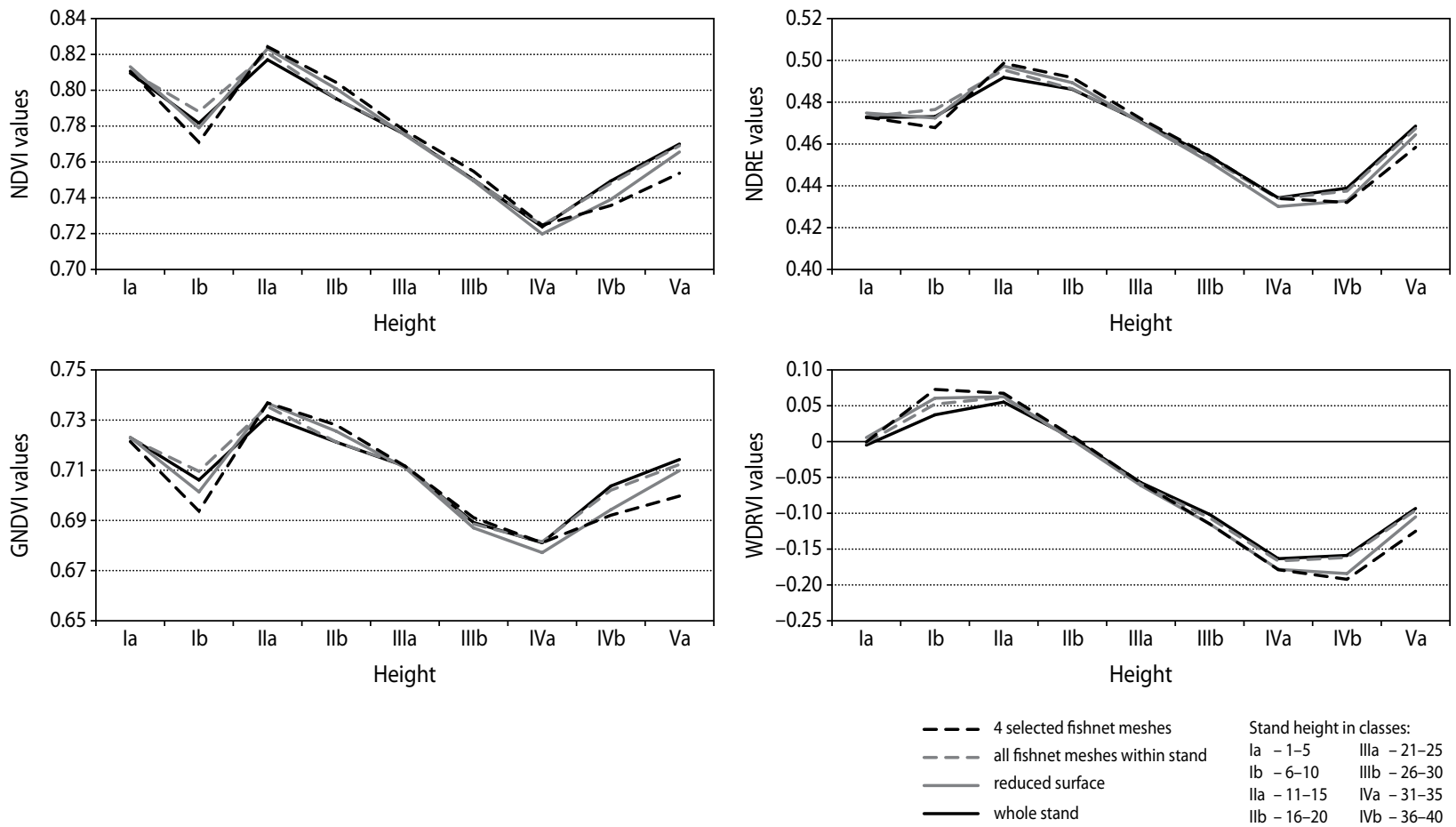

Stand height in classes:

la $-1-5 \quad$ IIla $-21-25$

lb $-6-10 \quad$ IIIb $-26-30$

Ila $-11-15 \quad$ IVa $-31-35$

$\mathrm{Ilb}-16-20 \quad$ IVb $-36-40$

Figure 6. Indices values compared to stand height in classes 

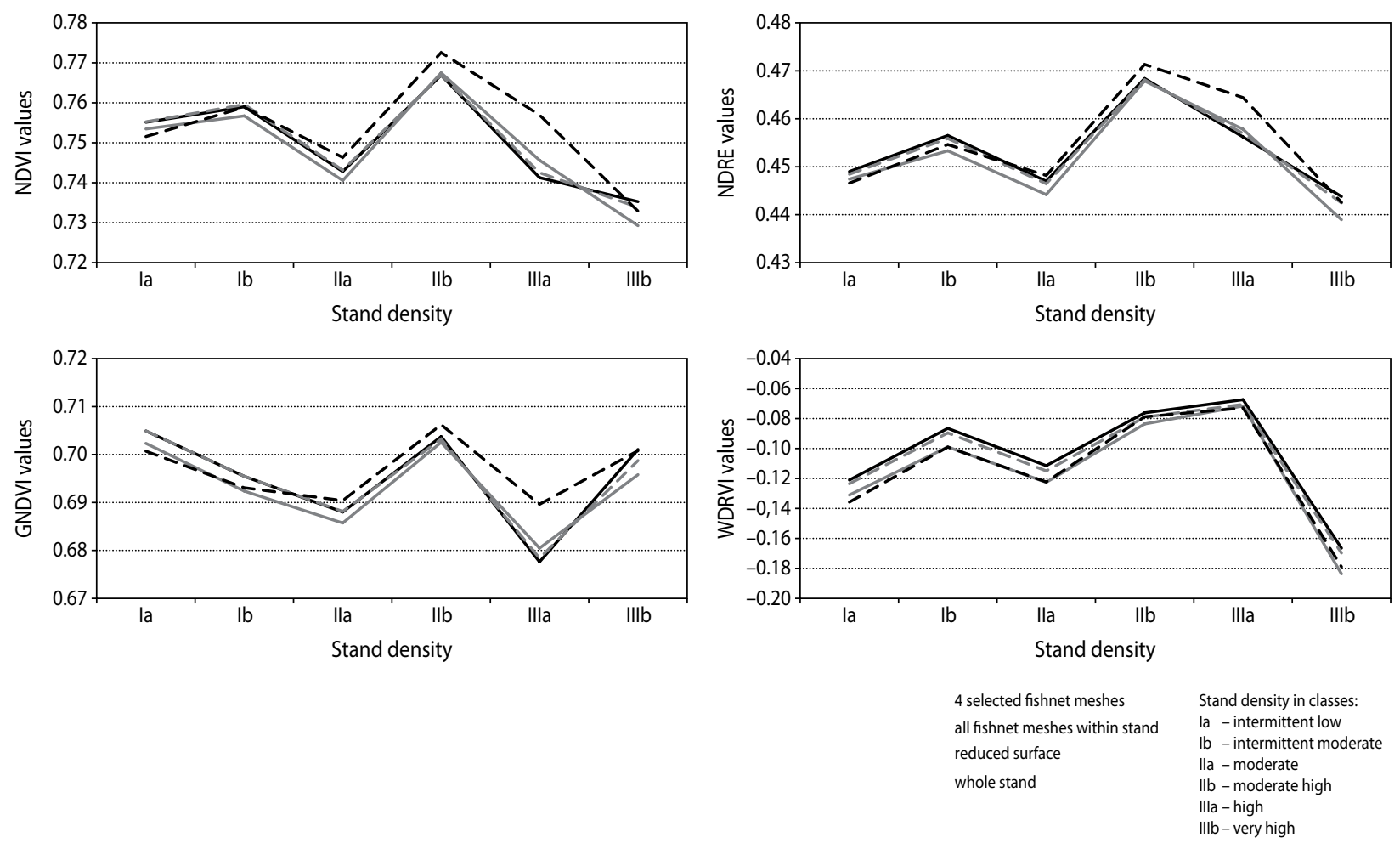

Figure 7. Indices values compared to stand density in classes
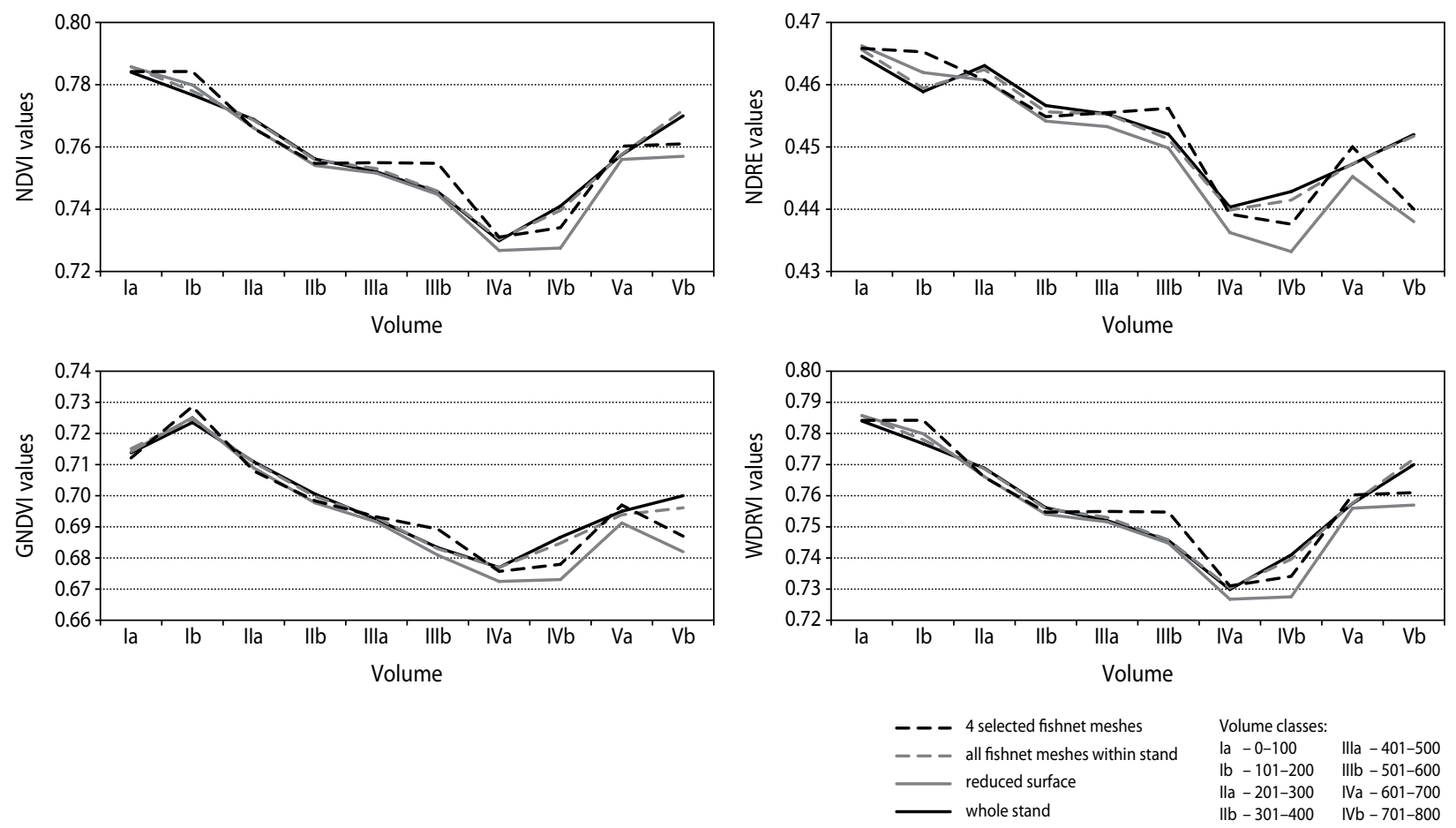

Figure 8. Indices response to the stand volume changes 
The change is lower, when the participation of spruce is higher. The same is seen for all the indices - the differences between values of indices on spatial levels seems to be more insignificant, when spruce participation is higher.

\section{Stand height}

In general, there was a similar trend for all the analysed indices as far as their relationship with tree height is concerned. High index values were observed for shorter trees (classes Ia-IIa). There is one significant decrease in Ib class for NDVI and GNDVI. The values become lower for heights between 16 and $35 \mathrm{~m}$ (height classes IIb-IVa), and even higher for trees taller than $35 \mathrm{~m}$ (Fig. 6). The average values for all indices are the lowest in the IVa class.

Analysing differences between response on different spatial standards, NDRE seems to be less sensitive to spatial changes - on each standard, average values are close. Standard deviations are lower for NDRE, which suggests this index is more stable. The results for other indices seem to be similar between IIa and IVa height classes, but for the youngest and the oldest trees, they are less stable and the difference between values for the whole stand and for selected meshes is bigger, especially in the case of GNDVI and WDRVI.

The general trends are similar for all indices, but changes between NDVI values in next height classes are much rapid than for rest of the indices. For GNDVI and WDRVI, the differences between response on another spatial standards are bigger, especially for stands with the highest and the lowest height. These differences are lower for NDRE.

\section{Stand density}

In all indices except for GNDVI, the response to stand density shows that values are lower in the first class (Ia) than in the next (Ib). A downward trend follows until the IIa class where values increase, before decreasing again right through to the IIIb class (again except from GNDVI). GNDVI reacts to the stand density changes in a different way than the other indices. Standard deviation is similar for NDVI, NDRE, GNDVI, where the biggest deviation was in the IIIa stand density class. But for WDRVI, standard deviation does not change that much with growing density changes (Fig. 7).
When the stand density is in Ia class, the values of all indices are low, except for GNDVI. In the next class (Ib), all indices are barely high; then they descend in moderate (IIa) class and go up in the next moderate high (IIb) class. For NDVI, NDRE and GNDVI, the values begin to decrease from the high-density class (IIIa), but GNDVI deviates from the rest, where the values decrease in the last class (Fig. 7).

\section{Volume}

The indices decrease with growing volume from Ia to IVa stand volume classes, but then they increase (Fig. 8). In all the indices, the IVa class recorded the lowest average, which means that the volume between 601 and 700 $\left(\mathrm{m}^{3} / \mathrm{ha}\right)$ probably corresponds with the worst condition. The highest values of indices are in the Ia class, where volume is lower than $100\left(\mathrm{~m}^{3} / \mathrm{ha}\right)$.

Generally, the averages of indices decrease with growing volume. The highest average corresponds with class Ia, where the volume is below 100. Only for GND$\mathrm{VI}$, the highest values are in Ib class, where the volume is between 101 and 200. The lowest average value for each index is recorded for volumes between 601 and 700 , but the averages increase thereafter. GNDVI is probably the most stable index - its averages on spatial standards does not differ as much as for the rest of indices. In the analysis of volume, NDRE are probably the less stable index.

\section{Diameter}

Diameter trends are shown to be relatively stable as compared to the previous volume, stand density and height trends. This is understandable given the known relationship between these characteristics. The highest index values correspond with a low diameter (II class). They are low in the previous class I, and in the next class, they increase to maximum. Then, with growing diameter indices, their values decrease. The lowest values are recorded when the diameter exceeds $30 \mathrm{~cm}$. Trends for all the indices are similar. From the III class to the last one, the indices NDVI, NDRE and GNDVI are on the same level, very close to the mean values from the first diameter class. Only WDRVI shows a significant decrease in the mentioned range. NDVI, NDRE and GNDVI averages are alike on each spatial standard and in each diameter class, the indices react similarly (Fig. 9). 

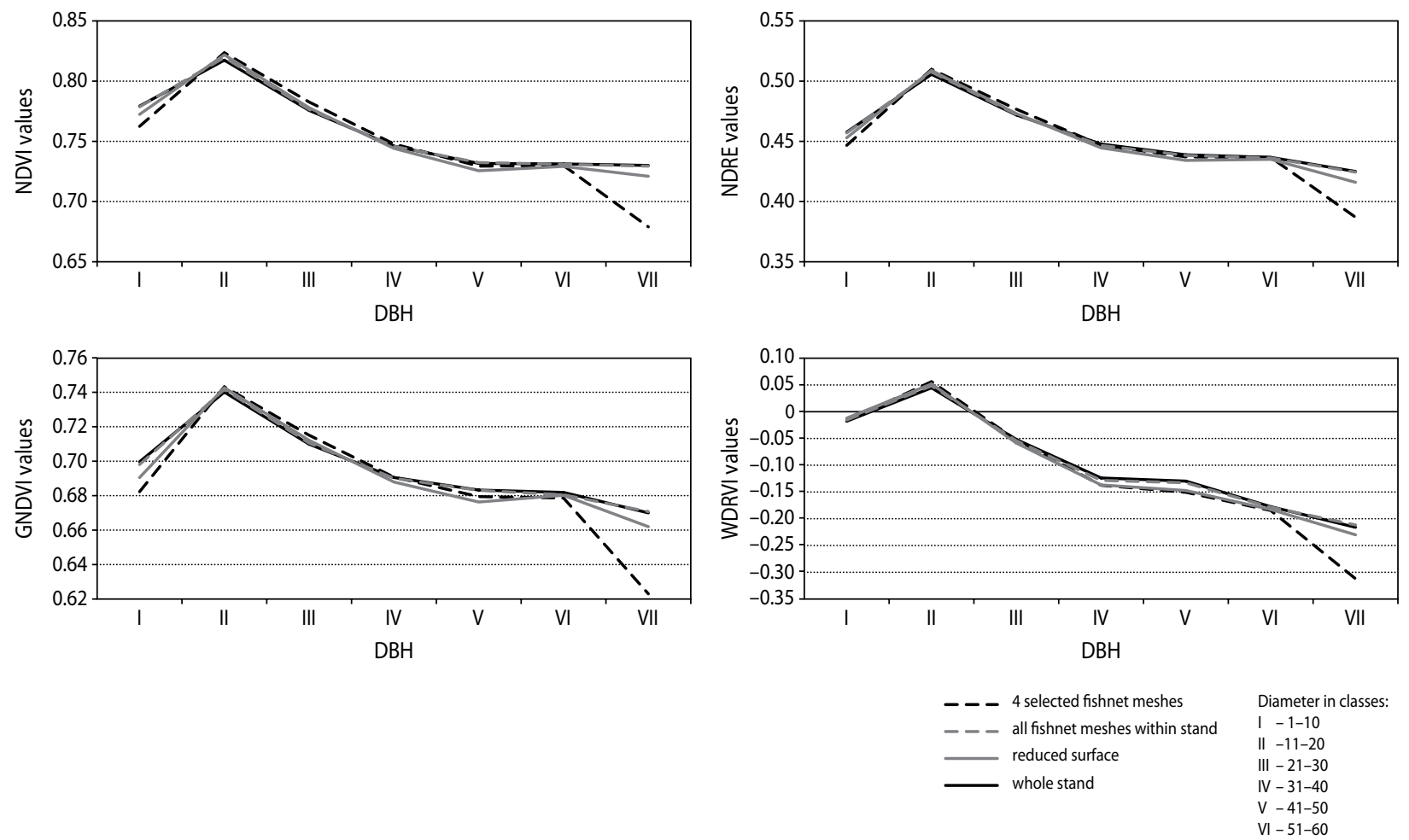

Figure 9. Relationship between indices values and diameter in classes

\section{Variation between Vegetation Indices Values}

The coefficient of variation values (Fig. 10) shows that all indices apart from WDRVI react similarly on each surface level with only slight variation. It indicates that it is not essential to select smaller areas and that the indices are stable. But the variations between levels for WDRVI is much higher, which refers to the lack of stability of the index.

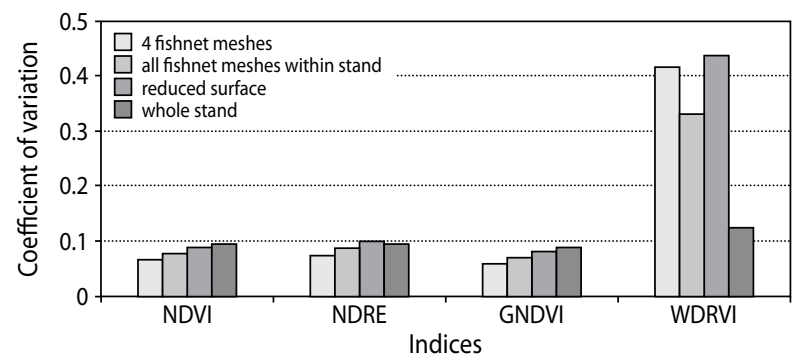

Figure 10. Coefficient of variation of vegetation indices

Nevertheless, WDRVI was found in this study to correspond well with the stand density. It is not surpris- ing that the WDRVI results corresponded with LAI (Gitelson 2004). Indices with the Red Edge band used in the formula gave good results. As NDRE was previously found effective for early damage detection (Eitel et al. 2011), it is also suitable for such spatial analysis. Additionally, the presented results can be used for correcting vegetation indices in relation to known information about forest or research areas. Although not many variants were presented in this study, it was based on a large number of cases, and therefore, adding to reliability.

\section{Discussion}

In this part, we would like to concentrate on reasons of indices variations. Another issue would be: which of the changes are actually related to forest vegetation condition alterations and which are most likely connected with stand parameters. 


\section{Spruce participation}

As it was mentioned in previous parts, the analysed stands were not fully homogenous - the actual participation of spruce in species composition were from 70 to $100 \%$. That is why, at first we had decided to analyse how the indices' responses change, when the spruce participation is lower than $100 \%$ and there are different species.

Each index has mostly high values when the spruce participation is lower. It is almost certainly related to broadleaved species participation, in which the reflectance is higher and increases indices. Greater share of other species translates into higher average reflectance and that influences the indices. When there is $100 \%$ of spruce, the spectral response is lower and the values of indices also decrease. Additionally, there is usually no other vegetation under spruce stands. This species usually has long crowns, sometimes longer than $2 / 3$ of the tree height, which results in very limited sun light reaching the ground under them. Usually, only dead biomass can be found. As a result, any reflection arising from understory usually denotes dead material. Furthermore, due to the crown's shape, the stands with spruce have a greater shadow area, which influences the reflectance. However, with more spruce contribution, indices seem to be more stable as there are no significant disparities between the values on spatial standards. When spruce participation is about $70-80 \%$, the differences are higher.

The disparities between indices response on different surface levels seem to be the lowest for NDRE. It makes that index constant for spatial changes. Response from the whole stand is most similar to reduced surfaces (Fig. 5). It suggests that the use of Red Edge band can improve index stability. Probably, NDRE is the most suitable index for spruce stands analysis.

\section{Height}

The stands analysed were with varying heights of the trees, from Ia to Va class. The highest trees were even higher than $40 \mathrm{~m}$. The general trend is similar to the volume relation between the indices, which was expected because of height correlation between the two stand characteristics. High index values are observed for shorter trees (classes Ia, Ib and IIa), where the nonforest vegetation may have a strong influence on the indices response. Values start to decrease when the height of trees is in IIb class $(16-20 \mathrm{~m})$, which should be related to higher shadow between trees. For this reason, the growth of low vegetation under spruces' crowns is lower and its participation in reflectance (what influences indices) is lower or insignificant. The mean values for all the indices are the lowest in the IVa class, where trees are between 31 and 35 meters, that is, the mature spruce stands. But another reason can be the lack of background vegetation response, which always makes values a bit higher. However, in classes IVb and Va, the values of vegetation indices are getting higher. It is most likely related to the contribution of the growing background vegetation, which occurs in high (old) stands.

In the first height class, where trees are short, the indices are high (Fig. 6). It is a result of the influence of lower background vegetation reflectance. In the next class IIb, where the trees are taller, the shadow is larger and there is not as much radiation as needed for low vegetation, the indices decrease. Additionally, there is a high competition between trees and many of them are dying in this stadium of stand development. It does not affect WDRVI, which does not decrease in the Ib class. The highest values of each index are recorded in the IIa class. It may be related to the fact that trees with heights in the 11-15 $\mathrm{m}$ range grow in high density areas and in many cases, with undergrowth vegetation, which does not suffer from lack of light. From IIb to IVa height classes, all index values are decreasing. It is similar to the trends presented in Figure 5.

As these are mainly spruce stands, that is, the tree growth causes a decrease in the undergrowth vegetation, which can - inter alia - affect changes in medium class response. The varieties of NDRE induced by height changes seem to be spatially stable, although between IIa and IVa classes, where the decline of indices values is recorded, there are no significant differences between stand and smaller standards in values for each index. Though there is a significant difference between the first class, where response is higher, and the last class. This discrepancy may be explained by the greater concentration of brushwood vegetation associated with the first class. Furthermore, as height and age are closely correlated, the age of stands could be the main contributing factor.

\section{Stand density}

When analysing the differences between the response of the analysed indices on particular surface standards, WDRVI seems to be the most stable when stand den- 
sity is high. In classes from IIb to IIIb, the curves for all standards are very close to each other, but seem to be slightly different in Ia-IIa classes. NDVI, NDRE and GNDVI respond in an inverse way. When the stand density is low (classes Ia-IIa), there are no significant differences in indices response, but in classes IIb-IIIb, the average for the 4 selected meshes is noticeably higher than for the whole stand and reduced areas.

When the stand density is intermittently low (Ia class), the values of all indices are low, except for GNDVI. It may be related to the sensitivity of this index to the green reflectance. In the next class (intermittent moderate stand density), all the index values are barely high, then descend in moderate class and then go up in the next, moderate high class. For NDVI, NDRE and GNDVI, the values begin to decrease from the highdensity class, but GNDVI deviates from the rest, where the values decrease in the last class (Fig. 7).

GNDVI has higher values in Ia and IIIa class, different than the rest of indices, which are low in these classes. The different response associated with GNDVI in the first and the last class could be considered as atypical, but it may be a result of green band usage. Also, the indices seem to be increasingly unstable when analysing its response to the stand density. These are more visible - and thereby, most likely significant - discrepancies between average values on each spatial standard, especially between the whole stand and the 4 fishnet meshes for moderate high and high stand density classes. WDRVI seems to be the most stable. In this case, we analysed the density of the first forest floor mainly consisting of spruce stands, which means that we received an incomplete picture of the situation. Under the first forest layer, different layers can be present if enough light penetrates the upper forest layers. Due to this, large variations are observed. What is common is that indices for dense stands have the smallest values, which is expected for spruce stands and similar for other analysed cases.

\section{Volume}

The highest values of indices are in Ia class of volume, where it is lower than $100 \mathrm{~m}^{3} / \mathrm{ha}$. It is the result of brushwood vegetation reflectance. The indices response seems to be highly variable and changes considerably with differences in volume.

In each case, there is a significant difference in the averages between the 4 fishnet meshes and the whole stand in classes IIIa and IIIb, that is, between 400-600 volume. Also, there are differences between classes with volume values above $700 \mathrm{~m}^{3} /$ ha. The values for the whole stand are higher than on the reduced surface. The standard deviation increases with higher volume (from 401 onwards) and is the highest in classes with volumes between approximately 500-700 for NDVI, NDRE and GNDVI. For WDRVI the situation is different, as the standard deviation is higher in Ia and IIb classes, before decreasing in higher volume classes.

Generally, the indices averages decrease with growing volume values. The highest average corresponds with class Ia, where volume is below 100. Only for GNDVI, the highest values are in Ib class, where the volume is between 101 and 200. The lowest average value for each index is recorded for volumes between 601 and 700, but averages increase thereafter. GNDVI seems to be the most stable and the differences on each standard seem to be less significant. NDRE is perhaps the most unstable in this case. However, changes are bigger when volume values are also bigger. There is also one noticeable difference between the response of the whole stand and the 4 fishnet meshes in class IIIb, where volume is approximately between 501-600. The highest volume was related with spruce stands, where other species such as alder, beech and aspen are present. It means that additional deciduous trees were responsible for this peak in the IVb and V volume classes.

\section{Diameter}

Analysing the relation between vegetation indices and diameter, it should be noticed, that there are no significant changes between the index values on different spatial standards. Especially NDVI and NDRE - curves have the same shape and mean values do not differ, when spatial standard changes. The same is true for GNDVI, but it seems to be less stable. There are more differences between spatial standards. Although standard deviation does not vary that much between all the aforementioned indices. The response of WDRVI is also similar and stable on each standard, but only when the diameter is low (below III class). The increasing diameter leads to less stable indices and average values for reduced surfaces are lower than that for the whole stand.

The difference between indices for low and high diameter depends on the index type. For example, WDRVI, differs more than NDVI and the rest. All the 
indices seem to react equally to changes in diameter. When the diameter is below $10 \mathrm{~cm}$, the values are on a moderate level, but increase when the diameter is between 11 and $20 \mathrm{~cm}$. Thereafter, they descend with increasing diameter values. The decrease for WDRVI, in high diameter classes is bigger than for the rest of the indices. From III to VI class, all indices apart from WDRVI are on the same level, close to the average values from the first diameter class. WDRVI is the one, which shows a decrease in the mentioned range. It suggests that indices NDVI, NDRE and GNDVI are independent from the diameter fluctuations. Spatial differences between particular levels seem to be insignificant, which means that indices are stable. There are some noticeable changes in GNDVI response, and also in WDRVI, when the diameter is greater than 30 .

All the analysed stand characteristics are influencing values of vegetation indices. In general, height, diameter at breast height, volume and spruce participation are the most negatively correlated with indices. Density is variable, which in general cannot directly be used for indices correction, because it is hard to find any stable trend. With the use of our results, it is possible to correct the index based on stand characteristics (measured in the field, or by remote sensing techniques or taken from existing forest digital maps) before condition analysis will be carried out.

\section{SUMMARY}

The performed analysis allows for following remarks:

1. All indices are lower when stand variables values increase.

2. The contribution of spruce has an influence on each of the indices.

3. NDRE is the most independent index. It is also the most stable on different spatial standards when spruce participation changes were analysed.

4. All indices are influenced by stand height. NDRE and WDRVI are less sensitive to this variable. NDRE is the most spatially stable index in terms of height variability.

5. Indices react differently to the stand density changes, but WDRVI is the most stable.

6. GNDVI is the most spatially stable index as far as volume changes are concerned.
7. Indices react equally on diameter changes. NDVI, NDRE and GNDVI are stable in diameter analysis. These indices are probably almost not sensitive to diameter changes.

8. Red Edge improves the spatial stability of indices for spruce participation and height analysis. NDRE is probably the best index for forest condition areas research - it is less sensitive to changes in stand parameters.

9. In most cases, the changes in indices' stability are insignificant; the response on the level of whole stand is the same as in the case of much subtracted area.

Based on the study, we can come to the following conclusions:

- All the analysed indices are suitable for forest condition analysis. However, forest stand parameters have an impact on the vegetation indices and that fact should always be considered.

- In analysis of forest stands health, using red edge spectral range improves the vegetation indices' stability.

\section{AcKnowledgments}

Data used in the research were available through the project 'Forest Condition Monitoring and Assessment in the Sudety and the Western Beskidy Mountains' conducted in the Forest Research Institute in Warsaw, financed by the Polish State Forests National Forest Holding.

\section{References}

Barnes E., Clarke T., Richards S., Collaizzi P., Haberland J., Kostrzewski M., Waller P., Choi C., Riley E., Tompson T., Lascano R., Li H., Moran M. 2000. Coincident detection of crop water stress, nitrogen status and canopy density using groundbased multispectral data. Proceedings of the 5th International Conference on Precision Agriculture, Bloomington, MN, USA (Madison, WI: ASACSSA-SSSA).

Buschmann C., Nagel E. 1993. In vivo spectroscopy and internal optics of leaves as basis for remote sens- 
ing of vegetation. International Journal of Remote Sensing, 14, 711-722.

Cho M., Debba P., Mutanga O., Dudeni-Tlhone N., Magadla T., Khuluse A. 2012. Potential utility of the spectral red-edge region of SumbandilaSat imagery for assessing indigenous forest structure and health. International Journal of Applied Earth Observation and Geoinformation, 16, 58-93.

Covington W.W., Fulé P.Z., Moore M.M., Hart S.C., Kolb T.E., Mast J.N., Sackett S.S., Wagner M.R. 1997. Restoration of ecosystem health in southwestern ponderosa pine forests. Journal of Forestry, 95, 23-29.

Eitel J., Vierling L., Litvak M., Long D., Schulthess U., Ager A., Krofcheck D., Stoscheck L. 2011. Broadband, red-edge information from satellites improves early stress detection in a New Mexico conifer woodland. Remote Sensing of Environment, 115, 3640-3646.

Food and Agriculture Organization of the United Nations 2016. GLOBAL FOREST RESOURCES ASSESSMENT 2015. How are the world's forests changing? Second edition.

Foody G.M., Cutler M.E., McMorrow J., Pelz D., Tangki H., Boyd D.S., Douglas I. 2001. Mapping the biomass of Bornean tropical rain forest from remotely sensed data. Global Ecology and Biogeography, 10 (4), 379-387.

Forest Data Bank 2014. URL: http://www.bdl.lasy.gov. pl/portal/mapy (Access: 19th Sep 2014).

Freitas S., Mello M., Cruz C. 2005. Relationships between forest structure and vegetation indices in Atlantic Rainforest. Forest Ecology and Management, 218, 353-362.

Gitelson A.A. 2004. Wide dynamic range vegetation index for remote quantification of biophysical characteristics of vegetation. Journal of Plant Physiology, 161 (2), 165-173.

Gitelson A.A., Kaufman Y.J., Merzlyak M.N. 1996. Use of a green channel in remote sensing of global vegetation from EOS-MODIS. Remote Sensing of Environment, 58 (3), 289-298.

Henerby G., Vina A., Gitelson A. 2004. The Wide Dynamic Range Vegetation Index and its Potential Utility for Gap Analysis. Papers in Natural Resources, 262, 50-56.
Heute A., Didan K., Miura T., Rodreguez E., Gao X., Ferreira L. 2002. Overview of the radiometric and biophysical performance of the MODIS vegetation indices. Remote Sensing of Environment, 83, 195-213.

Hicke J., Johnson M., Hayes J., Preisler H. 2012. Effects of bark beetle-caused tree mortality on wildfire. Forest Ecology and Management, 271, 81-90.

Houghton R.A., Lawrence K.T., Hackler J.L., Brown S. 2001. The spatial distribution of forest biomass in the Brazilian Amazon: a comparison of estimates. Global Change Biology 7 (7), 731-746.

Jackson R., Heute A.R. 1991. Interpreting vegetation indices. Preventive Veterinary Medicine, 11, 185-200.

Jenkins M., Hebertson E., Page W., Jorgensen C. 2008. Bark beetles, fuels, fires and implications for forest management in the Intermountain West. Forest Ecology and Management, 254, 16-34.

Jiang Z., Heute A., Didan K., Miura T. 2008. Development of a two-band enhanced vegetation index without a blue band. Remote Sensing of Environment, 112, 3833-3845.

Jordan C.F. 1969. Derivation of leaf area index from quality of light on the forest floor. Ecology, 50, 663-666.

Lu D., Mausel P., Brondízio E., Moran E. 2004. Relationships between forest stand parameters and Landsat TM spectral responses in the Brazilian Amazon Basin. Forest Ecology and Management, 198, 149-167.

Meigs G., Kennedy R., Cohen W. 2011. A Landsat time series approach to characterize bark beetle and defoliator impacts on tree mortality and surface fuels in conifer forests. Remote Sensing of Environment, $115,3707-3718$.

Rocha A.V., Shaver G.R. 2009. Advantages of a two band EVI calculated from solar and photosynthetically active radiation fluxes. Agricultural and Forest Meteorology, 149, 1560-1563.

Rouse J., Haas R., Schell J., Deering D. 1973. Monitoring vegetation systems in the Great Plains with ERTS. 3rd ERTS Symposium 1973, NASA SP-351 I, 309-317.

Rykowski K. 2008. Climate change, forest, forestry relationships. Centrum Informacyjne Lasów Państwowych, Warszawa. 
Todd S.W., Hoffer R.M. 1998. Responses of spectral indices to variations in vegetation cover and soil background. Photogrammetric Engineering and Remote Sensing, 64 (9), 915-921.

Weichelt H., Rosso P., Marx A., Reigber S., Douglass K., Heynen M. 2014. White Paper. The RapidEye Red Edge Band. Article on-line: URL: http://www. blackbridge.com/ (Access: 19th Jun 2014).

Weier J., Herring D. 2000. Measuring vegetation. Article on-line: URL: http://earthobservatory.nasa.gov/
Features/MeasuringVegetation/ (Access: 9th Oct 2014).

Woźniak E. 2011. Analysis of correlation between vegetation and fire intensity indexes: the case of forest fires occurred in Greece in 2007. Teledetekcja Środowiska, 45, 19-24.

Xiao Y., Zhao W., Zhou D., Gong H. 2014. Sensitivity analysis of vegetation reflectance to biochemical and biophysical variables at leaf, canopy, and regional scales. IEEE Transactions on Geoscience and Remote Sensing, 52 (7), 4014-4024. 